\title{
VIOLENCIA SOCIAL Y DISCURSO POLÍTICO PRESIDENCIAL VENEZOLANO: UN ESTUDIO PSICOSOCIAL
}

\author{
Luis Alberto d'Aubeterre Alvarado \\ Universidad Nacional Experimental de Guayana, Guayana, Venezuela
}

\begin{abstract}
RESUMEN: La creciente violencia cotidiana y la inseguridad social en Venezuela son percibidas como el problema nacional más grave de esta década y un serio asunto de salud pública. Junto con Brasil y México, la Organización Mundial de la Salud (OMS) clasificó a Venezuela entre los países con mayor violencia del planeta. Un aspecto menos notorio del problema es la violencia simbólica. El objetivo de este estudio documental exploratorio-hermenéutico fue abordar la violencia social como proceso complejo psico-socio-político-histórico, desde la psicología social discursiva, a partir del análisis del discurso político oficial del Presidente Hugo Chávez. El método empleado fue el análisis del discurso, aplicado a un corpus constituido por dos alocuciones presidenciales, publicadas en Internet. Los resultados sugieren que el discurso político presidencial venezolano reforzaría y legitimaría la violencia social del país y proveería elementos fundamentales para construir identidades sociales irreconciliables.
\end{abstract}

PALABRAS-CLAVE: violencia; guerra; discurso político.

\section{VIOLÊNCIA SOCIAL E DISCURSO POLÍTICO PRESIDENCIAL VENEZUELANO: UM ESTUDO PSICOSSOCIAL}

RESUMO: A crescente violência cotidiana e insegurança social na Venezuela são percebidas como o problema nacional mais grave desta década e, ao mesmo tempo, um assunto vinculado à saúde publica. Junto ao Brasil e México, a Organização Mundial da Saúde (OMS) classificou a Venezuela como um dos países com maior indicie de violência do planeta. Um aspecto menos notável é a violência simbólica. O objetivo deste estudo documental exploratório-hermêneutico foi abordar a violência social como um processo psico-socio-político-histórico, desde a psicologia social discursiva, a partir da análise do discurso político oficial do Presidente Hugo Chávez. O método utilizado foi a análise do discurso, aplicado a um corpus constituído por duas alocuções presidenciais, publicadas na Internet. Os resultados sugerem que o discurso político presidencial venezuelano reforçaria e legitimaria a violência social do país e proveria elementos fundamentais para construir identidades sociais irreconciliáveis.

PALAVRAS-CHAVE: violência; guerra; discurso político.

\section{SOCIAL VIOLENCE AND VENEZUELAN POLITICAL PRESIDENTIAL DISCOURSE: A PSYCHOSOCIAL STUDY.}

\begin{abstract}
The daily growth of violence and social insecurity in Venezuela are perceived as the most serious problems of this decade and a critical public health matter. The World Health Organization (WHO) classified Brazil, Mexico and Venezuela among the countries with the highest rates of violence in the world. Nevertheless, there is a less notorious aspect: symbolical violence. The aim of this study was to approach social violence as a psycho-socio-political-historical complex process, from a psychosocial discursive perspective. The starting point was the analysis of President Hugo Chávez's official political discourse. This is a documental exploratory and hermeneutical research: discourse analysis was the method applied on a corpus composed by two selected presidential allocutions published in the Internet. The results suggest that President Chavez's political discourse could reinforce and legitimize national social violence and provide fundamental elements to build emergent antagonist social identities.
\end{abstract}

KEYWORDS: violence; war; political discourse. 


\section{Introducción}

Durante la última década, uno de los aspectos más apreciables de la vida cotidiana de los venezolanos ha sido la violencia creciente en todos los espacios sociales. La inseguridad es percibida como el problema más grave del país y se entiende como un serio problema de salud pública global-local. Al inicio del milenio, la Organización Mundial de la Salud (WHO, 2000) calculó que en el mundo ocurrían unos 520.000 homicidios por año ( 8,8 asesinatos por 100.000 habitantes), mientras que las guerras produjeron unos 310.000 muertos (5,2 víctimas por 100.000 habitantes). Junto con Brasil y México, Venezuela está clasificada por la OMS entre los países con alta violencia en el planeta (21 a 30 homicidios por 100.000 habitantes). Asumiendo que la violencia no es una enfermedad tipológico-estructural de algunos individuos (Kretschmer, 1921), sino un complejo proceso psicosocial, tendríamos una definición de violencia ofrecida por Mora y Rodríguez (2004, p. 2): la violencia es "a) una acción física intencional, b) tiene como objetivo agraviar y castigar, c) se perpetra de manera unilateral en contra de los deseos de la víctima y d) puede ser face to face o simbólica". Por su parte, Kaés (2000, p. 249) coincide que "cualquier noción general de violencia incluye la acción intencional y unilateral para reducir al otro(s) a la impotencia y al sufrimiento", pero recomienda que "debe hablarse de violencia en un sentido heterogéneo - y plural, refiriéndose a violencias-: urbanas, familiares, policíacas, simbólicas, verbales, étnicas." Entre las explicaciones sociológicas recientes acerca de la violencia social en Venezuela, Briceño (2007, p. 551) propone un modelo con cinco tipos de factores: "dos de tipo situacional: el incremento de la desigualdad urbana y el aumento de la educación y el desempleo". Dos de tipo bisagra: "el incremento de la aspiraciones y la imposibilidad de satisfacerlas y los cambios en la familia". Y uno de tipo cultural... "la pérdida de vigor como controlador social, de la religión católica". Se entiende que el proceso de fragmentación social que experimentan las sociedades contemporáneas (y en particular, la sociedad venezolana), es producto de una creciente degradación de las condiciones y relaciones cotidianas de vida de la gente caracterizadas por: incertidumbre, inseguridad existencial, desempleo, bombardeo mediático, pobreza, drogadicción, exclusión y marginación de grandes cantidades de la población, lo cual ha provocado que las instituciones (familia, gobierno, escuela, Iglesia, empresa, mercado, medios masivos de comunicación, etc), no puedan otorgar sentido a la vida de las personas, por lo que paulatinamente la violencia destructiva dota a una gran cantidad de sujetos, de una vía idónea para expresar su existencia al mundo. En este sentido, Coronado (2007, p. 427) subraya que "el definitivo agotamiento institucional...va de la mano de un profundo resentimiento social... El debilitamiento de las instituciones, de las normas y los valores comunes... conduce al crecimiento de la inseguridad que está asechando en las calles".

\section{Sobre la violencia simbólica}

Un aspecto menos tangible de la violencia cotidiana a la cual están expuestas las personas, es la violencia simbólica del discurso. Pierre Bourdieu (1988) enriqueció el concepto de violencia, identificando la violencia simbólica, partiendo del supuesto que el poder simbólico literalmente construye un mundo imponiendo orden a la realidad. Cuando la violencia simbólica impone categorizaciones como condición de posibilidad para pensar el mundo, entenderlo, significarlo, etc., se trataría de una violencia necesaria, positiva, cultural. Empero, cuando se imponen categorías que impliquen un deber ser único, legítimo, adecuado o pertinente, borrándose toda huella de alternativas posibles, la violencia que se ejerce clausura los procesos mismos de pensamiento, cristalizando un estereotipo y un pensamiento único instituido como normal. Ello supone la invisiblización de alternativas, bajo un mecanismo de "naturalización". Entre los modos discursivos retóricos usuales que asume el ejercicio de la violencia simbólica están: la descalificación constante, la imposición de opinión o su silenciamiento, la interrupción, la banalización, la falta de reconocimiento, la invisibilización de los intereses y de las necesidades del otro(a) etc. Si bien puede argumentarse que de esta agresión no hay ni heridas ni sangramiento visibles, la violencia simbólica propende a derivar en ataques físicos, muchas veces en términos correctivos, dependiendo del lugar de origen y del estatus psico-socio-político de donde ella procede.

Desde nuestra perspectiva, proponemos definir la violencia como una acción destructiva física o simbólica contra Otro o contra Sí mismo, que se construye socialmente según códigos simbólicos compartidos que hacen parte del sentido común de un colectivo, en un tiempo-lugar históricamente definido. La expresión discursiva de la violencia recurre a símbolos verbales para impactar al Otro o a Sí mismo, en sus tres dimensiones de existencia: real, simbólica e imaginaria. Mediante la violencia discursiva se impone la asignación de atributos cuya intención es: negativizar al individuo, negarlo como semejante, denigrar su condición social, a fin de construirle una identidad social despreciable que pudiere justificar su aniquilación. 


\section{Algunos presupuestos teóricos}

Partiendo del construccionismo social (Berger y Luckman, Gergen, Ibáñez) y la psicología discursiva (Billig, Parker, Potter y Wetherell), se asumen algunos supuestos teóricos: (a) el discurso es un sistema de afirmaciones que construye un objeto y una praxis socio-antropológica fundacional: funda la realidad de la cual habla, sin que ello reduzca la realidad a lo que el discurso dice de ella; (b) el sentido común es una dimensión transdiscursiva cargada de la sedimentación de contenidos semánticos que palabras y discursos, atesoran, adecuan y transforman a lo largo de la historia de cada sociedad; (c) la identidad social es un proceso-producto dialógico de confección colectiva del tejido semántico delimitador de narrativas identificatorias tanto del colectivo originario (Nostredad) y del Yo discursivo del sujeto, como de la alteridad del "Otro-diferente-queyo" (Otredad); (d) La violencia discursiva, si bien no deja huellas físicas inmediatas, tiene profundos efectos psico-sociales en los individuos creando condiciones propicias para el acto consumatorio.

\section{Aspectos conceptuales básicos del estudio}

A partir de los primeros desarrollos clásicos de Marx y de Engels en 1846, buena parte de la literatura de las ciencias sociales y de la filosofía contemporáneas ha girado en torno al concepto de ideología, definida como la expresión de las relaciones materiales dominantes concebidas bajo la forma de pensamientos. Se trataría de "un proceso que el pensador desarrolla concientemente pero con una falsa conciencia. Las fuerzas motrices verdaderas que lo ponen en movimiento le son desconocidas; de otra forma ello no sería un proceso ideológico". Marx aclara más adelante que "la ideología, casi por entero se reduce, bien sea a una concepción errónea de esa historia, bien sea a una completa abstracción de esa misma historia" (Marx, 1966, pp. 140-141). Apoyándonos en la revisión crítica de Montero (1994) y los aportes de otros psicólogos sociales (Billig, 1991; Páez, Valencia, Morales, Sarabia, \& Ursua, 1998), se propone definir la ideología como un sistema discursivo prescriptito, sesgado, que impone como condición retórica un bloqueo a la discrepancia argumentativa y procede a la distorsión interesada de lo que se dice, en función de preservar los intereses y el poder de grupos socialmente dominantes. El discurso ideológico se construye como un relato totalizante, intencionalmente falsificador de la realidad social, mediante el cual se posiciona al individuo en una red de relaciones y de sentidos que prescriben y delimitan roles, atributos, privilegios, expectativas, etc., ligados al ejercicio del poder
(d'Aubeterre, 2003). Consecuentemente, una Configuración Ideológica es una figura discursivo-semántica que emerge de las creencias emitidas en un fragmento discursivo y contiene argumentos absolutos ("verdades obvias"), sobre determinados tópicos-objetos que son abstraídos de su particular contexto histórico, resemantizando de manera sesgada la realidad de la cual se habla, al transformar hechos socio-políticos concretos en objetos discursivos abstractos, aislados.

Otro de los conceptos clave de este estudio es el mito. Al igual que la ideología, el mito mantiene una relación fundamental con el sentido común que las personas construyen a partir de sus prácticas discursivas. Éste puede definirse como una historia que se enuncia y se deja oír, sea como un "relato de orígenes" (Eliade, 1978), sea como una "palabra truqueda" (Barthes, 1970), cuya temporalidad es a-crónica (in illo tempore) pero que en ambos casos, vacía a su objeto discursivo de toda significación socio-política, transformándolo en una esencia, a-histórica, "inocente" y "natural". La finalidad del mito sería evacuar la realidad, transmutar la historia en "naturaleza" y en consecuencia, inmovilizar el mundo e instalar la eternidad en su seno, creando una suerte de mismidad ("siempre lo mismo"), obsesivamente presente. Así pues, definimos una configuración mitológica, como una figura discursivo-semántica que emerge de las creencias emitidas en un fragmento discursivo y puede adquirir dos formas enunciativas: un "relato de orígenes" que habla del nacimiento o emergencia de algo que "siempre" ha existido socialmente, o bien una "palabra truqueada" que discurre de forma "ingenua" describiendo un objeto social concreto, como si fuese una "esencia natural pura".

En este entramado conceptual que nos ha permitido una aproximación discursiva de los procesos psicosociales cotidianos, se contemplan también los conceptos de creencia y sentido común. Usualmente, el término creencia se emplea en plural (Fishbein \& Ajzen, 1975; Gergen \& Keith, 1985; Páez et al., 1998). Las creencias, en tanto objetos intangibles que la gente intercambia todos los días cuando afirma, contradice, defiende, niega, o critica, están hechas de la misma materia fluida y efervescente que construye al mito, a la ideología y al sentido común: los discursos. El rasgo característico de las creencias es que ellas se refieren a proposiciones o enunciados que son tomados como verdaderos. Se definirá como creencia: toda aquella proposición afirmativa explícita o implícita, que refleje/ exprese en el discurso la convicción de verdad que un interlocutor tenga respecto a un objeto, independientemente de la veracidad objetiva de dicha afirmación. En cuanto al sentido común, un supuesto teórico que parece asumible es que todas las formas de cognición social (creencias, valores, representaciones sociales, 
opiniones, prejuicios, mito...), que hacen parte del habla cotidiana de la gente, están vinculadas de múltiples formas con la ideología y con el sentido común. Así pues, los trabajos de psicología social discursiva desarrollados por Billig y colaboradores (1988), plantean que el sentido común contiene temas contradictorios que permiten la emergencia de los dilemas sociales e implican el material retórico a través del cual la gente argumenta, discute y piensa acerca de su vida y la de los demás. En otra parte (d'Aubeterre, 2007), hemos definido el sentido común tanto como (a) una dimensión transdiscursiva cargada de la sedimentación de sentidos semánticos que las palabras y las expresiones populares han ido atesorando, adecuando y transformando a lo largo de la historia de la lengua y hablas de cada sociedad, asimilando y adaptando materiales muy diversos: afirmaciones oficiales, juicios y dogmas religiosos, saberes (legales o proscritos), historia, chistes, juegos, chanzas, chismes, información de los noticieros, mitos, dichos, canciones, propaganda, publicidad, etc., y (b) un proceso-producto dialógico de hermenéutica social (Gadamer, 1992), característico de las prácticas discursivas, a saber: producir, generar, inventar significados y representaciones actuales que permitan hacer congruentes, asimilables, familiares y manejables los eventos que acaecen en los espacios de la vida cotidiana.

\section{Objetivos del estudio}

El objetivo general de este estudio fue abordar el problema de la violencia social en Venezuela, en tanto proceso complejo psico-socio-político, desde una perspectiva psicosocial discursiva, mediante el análisis de las producciones retóricas del discurso político oficial del Presidente Hugo Chávez, mientras que los objetivos específicos fueron: analizar las creencias dicotómicas y las configuraciones mitológicas e ideológicas del discurso presidencial, a fin de interpretar sus posibles efectos de violencia simbólica sobre la población.

\section{Aspectos metodológicos}

Se trata de un estudio documental exploratoriointerpretativo de corte hermenéutico, cuyo método es el análisis del discurso, aplicado a un corpus constituido por dos alocuciones presidenciales transcritas y publicadas en el sitio Web www.alopresidente.gob.ve, seleccionadas al azar: el programa $\mathrm{N}^{\circ} 285$, realizado en Elorza (Estado Apure), el domingo 10-06-07 durante la inauguración de una fábrica socialista de productos lácteos (Venezuela, 2007) y el programa No 300 , realizado en San Francisco de Tiznados, municipio Ortiz
(Estado Guárico), el domingo 13-01-08, durante la inauguración de un sistema de riego (Venezuela, 2008). El procedimiento de análisis del discurso que se siguió fue el siguiente: (a) se descompuso la totalidad del texto en fragmentos con sentido semántico completo; (b) se subdividió cada fragmento en oraciones o grupos de oraciones a fin de percibir más claramente, la presencia de tópicos-objetos recurrentes en el discurso que permitían aglutinar el sentido semántico del discurso; (c) para cada fragmento, se determinaron las Presuposiciones e Implicaciones no explícitas, pero inferibles del sentido semántico propuesto en las oraciones de cada fragmento discursivo; (d) se analizaron y contrastaron las Presuposiciones e Implicaciones obtenidas en cada fragmento del discurso, con la literalidad del fragmento, a fin de generar una matriz-síntesis de Creencias Dicotómicas (positivas/negativas), sobre todos los Tópicos-Objetos abordados a lo largo del discurso, y (e) finalmente, se identificaron e interpretaron las Configuraciones Ideológicas y Mitológicas del discurso que fueron detectadas en algunos fragmentos del discurso. En general, el análisis se focalizó en los fragmentos en los cuales se generaban argumentos relativos a los Tópicos-Objetos recurrentes en cada una de las alocuciones presidenciales. Las matrices de creencias dicotómicas que aquí se presentan, son producto de una integración sintética de las creencias emitidas en cada una de las dos alocuciones aquí consideradas como Corpus Discursivo del estudio.

\section{Análisis de los resultados}

Como puede apreciarse en las Matrices $\mathrm{N}^{\circ} 1$-a y $\mathrm{N}^{\circ} 1-\mathrm{b}$, la casi totalidad de creencias dicotómicas emitidas en el discurso presidencial en relación al tópico-objeto La Guerra, fueron positivas. El argumento principal para construir esta positividad de "La Guerra" es histórico pues se afirma que tanto la historia de Venezuela como la historia de América Latina se ha visto marcada por la guerra desde la llegada de los conquistadores españoles, pasando por las luchas independentistas hasta nuestros días. La Guerra emerge así como una constante histórica plena de héroes: indígenas precolombinos luchando contra el colonizador de España y los héroes consagrados por la guerra de Independencia de las Américas (Bolívar, Páez, San Martín). Se produjo una trilogía de tópicos-objetos que configuran los aglutinadores semánticos a partir de los cuales se legitima La Guerra, a saber: La Historia, Los Héroes y La Revolución. La retórica discursiva presidencial, legitimadora de la guerra, recurre a una conjugación de tiempos históricos que permite una especie de identidad trans-histórica de todas las revoluciones 
y de todos los héroes luchadores contra la opresión de los imperios (independientemente de sus particulares condiciones y contextos socio-histórico-culturales y político-económicos), todas las revoluciones se parecen: la Revolución Francesa, la Revolución de Independencia, la Revolución Bolivariana.
En cuanto a las cuatro únicas creencias negativas registradas sobre La Guerra, todas se refieren a la actual "guerra civil de Colombia" entre la guerrilla (FARC y ELN) y el Gobierno colombiano, de la cual se afirma paradójicamente que si bien "es inhumana" y "no es humanizable", no obstante es menester "tratar

\section{MATRIZ N $\mathrm{N}^{\circ} 1$-a \\ Tópico-Objeto: LA GUERRA}

Creencias Positivas

Creencias Negativas

-Toda la historia de Venezuela preco-lombina, colonial y contemporánea está marcada por la guerra

-Venezuela siempre ha sido una tierra de batallas: ayer fue la lucha de los indígenas contra el colonizador español, luego fue la guerra por la Independencia y hoy es la guerra contra el imperio y la soberanía nacional.

-La lucha político-ideológica y eco-nómica que se plantea entre el socia-lismo del Presidente Chávez y el capita-lismo imperialista norteamericano, es una Guerra Santa entre el Bien (Dios/ Cristo) y el Mal (el Diablo/ gobierno USA).

-Al igual que Bolívar y Morillo firmaron un Tratado de Regularización de la Guerra, Chávez, la Guerrilla y el Presi-dente Uribe, podrían firmar otro tratado de pacificación de la guerra civil de Colombia.

-El terrible español, General Morillo, vino a pacificar la Guerra a Muerte, con el ejército más grande que España man-dó a tierra firme; fue a Colombia, a Cartagena la heroica, y la sitió y la destruyó, pero no logró capturarla, y luego vino a Venezuela, a Apure y fue derrotado por los llaneros, los centauros del Llano. -Si antes hubo guerra en El Salvador, Nicaragua y Guatemala y ahora hay democracia y paz, en Colombia también es posible.

-La solución de la guerra civil en Colombia pasa por la aceptación de las FARC por el Gobierno colombiano.

-La divisa del gobierno del Presidente de Chávez es una expresión de guerra: "patria, Socialismo o muerte"...

-La única opción de vida de la patria, es la de la lucha revolucionaria por el socialismo: el capitalismo es la muerte.
-La guerra es inhumana, por eso hay que tratar de humanizar la guerra civil de Colombia aplicándole el Protocolo de Ginebra. -La guerra no es humanizable.

-La guerra civil colombiana le ha costado a Venezuela muchos heridos, muertos, secuestrados, pérdidas econó-micas, inseguridad, etc, en los territo-rios fronterizos.

-Ya basta de 60 años de guerra civil en Colombia.

\section{MATRIZ $\mathrm{N}^{\circ} 1-\mathrm{b}$ \\ Tópico-Objeto: LA GUERRA}

Creencias Negativas

-Todos los revolucionarios bolivarianos están dispuestos a morir luchando por la patria socialista, en contra del impe-rio norteamericano.

-"Patria, socialismo o muerte", no es una amenaza de muerte del Presidente Chávez: es que se quiere evitar la muerte.

-Los héroes de la guerra de Inde-pendencia están vivos y vigentes en el presente político de la revolución bolivariana.

-Tanto ayer como hoy, los guerreros venezolanos luchan contra un imperio para logar su independencia.

-Toda la historia latinoamericana de los últimos 100 años, se reduce a la guerra contra el imperialismo norteamericano.

-La revolución bolivariana socialista es una guerra a muerte contra el imperia-lismo capitalista de los USA.

-En Venezuela y en el mundo, hay una lucha de clases entre los ricos burgue-ses y los pobres. 
de humanizarla ... aplicándole el Protocolo de Ginebra" (Venezuela, 2008). En suma, se afirmó creer que "ya basta de 60 años de guerra" fraticida en Colombia que además, ha venido afectando seriamente a Venezuela a lo largo de su frontera. Resulta interesante notar que esta puntual negatividad discursiva que adopta el tópico-objeto La Guerra, se esgrime para defender la polémica propuesta política internacional que desde el 2007 ha hecho el Presidente Chávez al Presidente Uribe de Colombia, relativa a conceder a las FARC y al ELN el estatus de "grupos beligerantes con un proyecto político revolucionario", eliminando así su muy crítica condición actual de terroristas ante la opinión pública mundial y los entes supra-nacionales (ONU, OEA, Unión Europea, etc.). El Presidente Chávez afirma creer que: "Para que se acabe la guerra civil de Colombia, el gobierno colombiano debe reconocer a las FARC $\mathrm{y}$ al ELN como un grupo insurgente y no un grupo de terroristas" (Venezuela, 2008, pp. 22-23). La gran cantidad de creencias positivas emitidas por el discurso presidencial sobre La Guerra, construye un argumento legitimador de la violencia social, en tanto escenario "natural" constitutivo de la historia venezolana donde se desplegarían las mejores y sublimes cualidades: heroicidad, carácter guerrero, viril, patriótico, de los venezolanos, guiados por el ejemplo dignificante del panteón de héroes que en s. XIX dieron sus vidas por la libertad de este país: Los héroes de la guerra de Independencia están vivos y vigentes en el presente político de la revolución bolivariana. En este sentido, una de las configuraciones mitológicas detectada entre las matrices de creencias dicotómicas, consiste en concebir La Guerra como dimensión trans-histórica, mágica, que permitiría el re-encuentro contemporáneo con los ancestros fundadores de La Patria (Los Héroes de la guerra de Independencia), en la medida en que "la revolución bolivariana" de hoy revive el pasado revolucionario en el cual Tanto ayer como hoy, los guerreros venezolanos luchan contra un imperio para lograr su independencia. Todo lo cual nos refiere a una temporalidad no-cronológica, a-histórica, propia del tiempo mítico de las fundaciones (Eliade, 1978). Esta forma retórica de construir discursivamente La Guerra como algo positivo, nada tiene que ver con las contingencias destructivas sangrientas, crueles, materiales, morales, que supone toda guerra real entre ejércitos humanos y máquinas de muerte que se enfrentan para matarse, destruir y vencer al enemigo. Empero, se recurre retóricamente al espectro macabro de La Guerra y la muerte, para adornar con el prestigio glorioso de Los Héroes fundadores y su ejemplaridad prometéica, las proposiciones político-ideológicas actuales del Presidente Chávez que afectan la totalidad de las prácticas cotidianas de vida de las personas y de las instituciones del Estado. Como todo llamado a la guerra, éste no apela a la razón (logos), sino a la irracionalidad de las pasiones y sentimientos (pathos) que propician la identidad y compactación grupal, y a menudo se recurre a eslogans o divisas reiteradamente repetidas que se asumen como un lugar común que poco a poco se asimila como una "verdad obvia" compartida por todos. Es el caso de la frase exaltante que desde hace unos dos años viene enunciándose en el discurso presidencial por todos los medios de comunicación social: "Patria, socialismo o muerte", la cual cristaliza de manera sintética e implícita el discurso apologético de La Guerra y su violencia más radical. Sintomáticamente, entre las creencias positivas del discurso presidencial surgió una que propone justificar dicho eslogan: "Patria, socialismo o muerte, no es una amenaza de muerte de Chávez: es que se quiere evitar la muerte". Cosa que resulta difícil de imaginar cuando la guerra tanto anunciada, verdaderamente ocurre.

Respecto a las creencias relativas al tópico-objeto La Revolución, nuevamente emerge un vaso comunicante trans-histórico entre los tiempos de las revoluciones ejemplares del pasado y la revolución bolivariana. La Matriz $\mathrm{N}^{\circ} 2$, permite observar que las creencias sobre el tópico-objeto La Revolución, confeccionan una positividad discursiva basada en dos argumentos: primero, una vez más, la retórica del discurso presidencial permite construir una vinculación histórica simbólica e imaginaria entre procesos socio-políticos ubicados en tiempos, espacios y contextos culturales muy distintos, afirmando relaciones de equivalencia o igualdad (si no, de continuidad): "Todas las revoluciones se parecen..."; "Todos los revolucionarios se parecen". Ambas creencias sugieren una casi identidad entre hechos históricos tales como: la Revolución Francesa, la Revolución de Independencia, la Revolución Bolivariana, lo mismo que una equivalencia entre personajes históricos tales como Robespierre, Marat, Bolívar, Ribas y Chávez. Las creencias que permiten delinear este argumento sugieren una configuración mitológica que emerge repetidas veces a lo largo de todo el Corpus Discursivo de este estudio, es decir: la existencia de un continuum transhistórico mágico, entre la revolución independentista emprendida por Bolívar contra el imperio colonial de la Corona española a finales del s. XIX y la revolución bolivariana comandada por el Presidente Chávez en este siglo XXI. Lógicamente, se produce también un efecto de continuidad trans-histórica del rol heroico que cada personaje desempeña en una y otra revolución. De esta forma se logra el efecto retórico de asignar al Presidente Chávez la continuación en el presente, de la gesta independentista realizada por Bolívar en el pasado. Por supuesto, ambos tiempos no son ubicables en la cronología objetiva de hechos históricos, sino 
en el tiempo a-crónico propio del mito. El segundo argumento sobre la positividad del tópico-objeto $\mathrm{La}$ Revolución, es que a través de la revolución socialista se lograría la libertad plena y la soberanía a todos los niveles: alimentario, científico-tecnológica, políticoeconómica, etc., "independiente del mundo capitalista", lo que supondría una total autosuficiencia alejada de las profundas relaciones de dependencia general, que han caracterizado la realidad político-económica de Venezuela. Este argumento pretende reforzarse a partir de un modelo exitoso de revolución, el de la República islámica de Irán, de cuya revolución se afirmó creer que es parecida a la revolución bolivariana ("pues también ha sido una colonia petrolera de los USA"). Así pues, se presenta a Irán como un aliado incondicional y desinteresado del gobierno del Presidente Chávez, con quien firmará un convenio de transferencia tecnológica, para que el país deje de importar tecnología foránea y aprenda a producir la tecnología iraní. La única creencia negativa relacionada con La Revolución, se emitió en contra de "los jóvenes estudiantes" universitarios que han protestado contra el gobierno, afirmando que se trata pequeños grupos manipulados, sin ideas propias y que defienden los "Intereses de la oligarquía". Cabe hacer notar que una constante retórica en las producciones discursivas del Presidente Chávez aquí analizadas, consiste en conectar de manera consistente (aunque a veces contradictoria), las creencias emitidas sobre los otros tópicos-objetos del discurso presidencial, produciendo así un efecto de circularidad reiterativa.

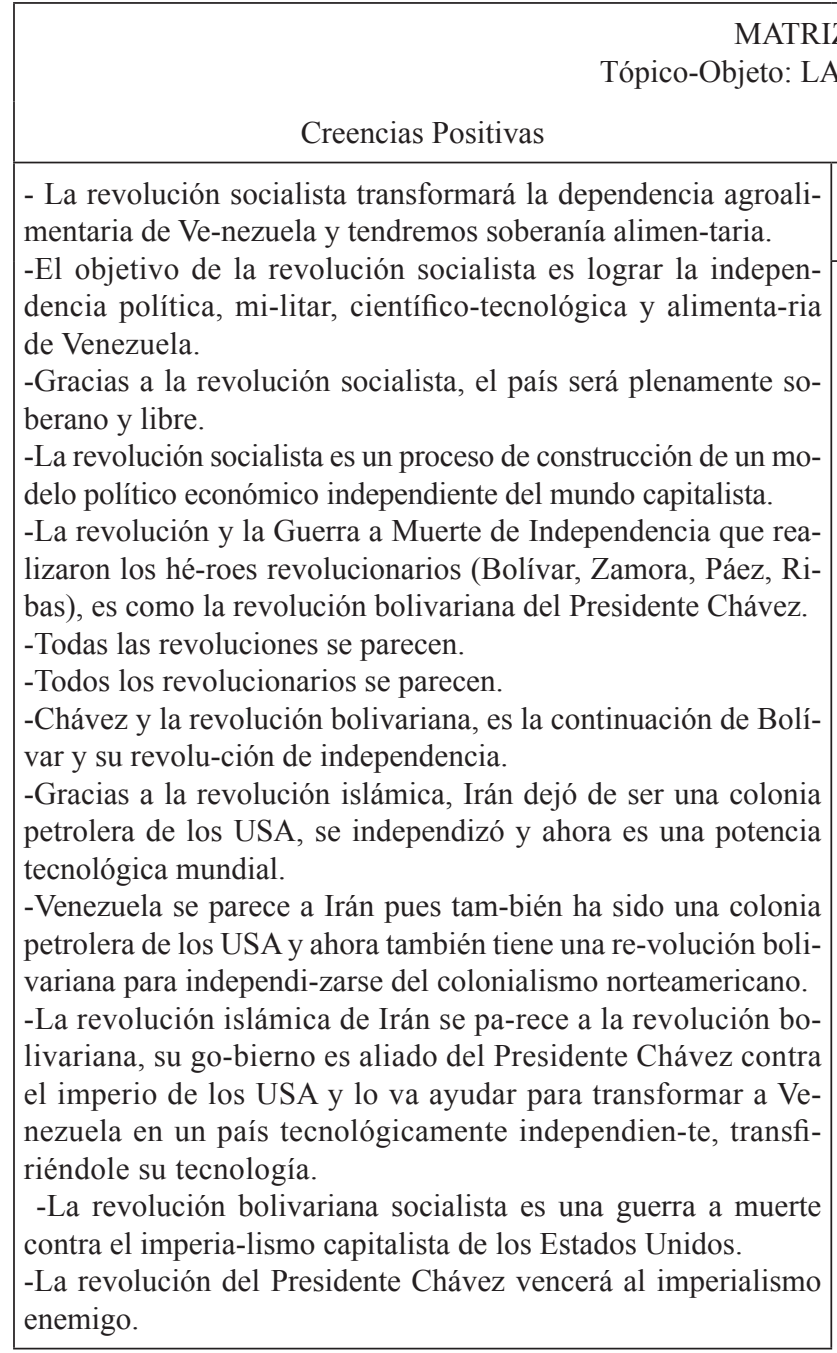

Las Matrices $\mathrm{N}^{\circ} 3$-a y $\mathrm{N}^{\circ} 3-\mathrm{b}$, cuyo tópico-objeto es La Historia, permiten apreciar al menos tres argumentaciones generales que agrupan las creencias positivas emitidas explícita o implícitamente en las dos alocuciones presidenciales consideradas en este estudio, según que se refieran a: (a) su interpretación sobre el relato heroico; (b) su lectura a partir del conocimiento del Presidente y (c) la disyuntiva histórica contemporánea. El primer grupo de creencias retoma el argumento que ya hemos detectado como una configuración mitológica, 
a-crónica y trans-histórica reiterada en las producciones discursivas presidenciales. Así tenemos nuevamente que el tópico-objeto La Historia se construye discursivamente como un relato ejemplarizante acerca de guerra, batallas y héroes (invencibles, valientes, revolucionarios, vencedores, inmortales), cuya vigencia sería más actual que nunca, puesto que sirven de referencia del pasado para entender el presente histórico-político que vive Venezuela (con lo cual se refuerza la mitologización de la historia) y, además, serían ejemplo para los nuevos guerreros de la revolución bolivariana socialista. La segunda categoría de creencias acerca de La Historia, se refiere a un aspecto característico del discurso presidencial: su constante referencia a relatos, anécdotas, citas, referencias, sobre la Historia nacional o universal y sobre su historia personal, narrados de forma amena para ilustrar algún aspecto de la política, venezolana o foránea, actual. Este procedimiento retórico del discurso presidencial permite confeccionar una configuración mitológica en torno al Presidente Chávez, que lo representa como un profundo y experto conocedor de la historia, capaz de desentrañar el significado político de 
los hechos del pasado en conexión directa con el presente y el futuro del país y el mundo. La Historia emerge así, como un mito cuyo tiempo circular nos reenvía a los tiempos primigenios de la fundación de la Patria y de la gesta monumental de Los Héroes de la Guerra de Independencia: así las cosas, el pasado se re-actualiza en el presente, cambian los actores, pero los hechos son "siempre" esencialmente los mismos: "tanto la historia del pasado como la historia del presente: ambas son una guerra a muerte por la patria: Patria, socialismo o muerte". La Historia pasa a ser un tópico-objeto omnipresente pues permite legitimar La Guerra y al Héroe, entendidos como elementos orgánicos indispensables de la trama existencial del país, que retoman el sempiterno problema del génesis y la "paternidad" de la nación: de allí la creencia implícita en el discurso según la cual Bolívar y Chávez son los dos padres libertadores y fundadores que ha tenido la Patria: el primero la libertó del imperio español y fundó la $1^{\mathrm{a}}$ y la $2^{\mathrm{a}}$ República, el segundo la estaría liberando del imperio estadounidense y fundó la $5^{\text {a }}$ República. Todo lo cual resulta congruente con la tradición histórica que en Venezuela existe adrededor del caudillo: personaje legendario marcado por un destino heroico excepcional que nutre el imaginario colectivo y el sentido común de los venezolanos y que el Presidente Chávez parece personificar consciente y cabalmente, por ejemplo, al proponerse como intermediario en el proceso de pacificación de la guerra civil en Colombia. En cuanto al tercer argumento implícito en la positividad que construyen las creencias sobre La Historia, relativas

Creencias Positivas
Tópico-Objeto:
-El Libertador Simón Bolívar fue el primer líder latinoamericano
que advir-tió que los USA es una nación hostil que haría mucho
daño a los países de América Latina, en nombre de la Libertad.
-Simón Bolívar y luego José Martí, fue-ron los primeros antiim-
perialistas con-tra los USA.
-Los héroes de la guerra de Indepen-dencia están vivos y vigen-
tes en el pre-sente político de la revolución boliva-riana.
-Los jóvenes líderes estudiantiles boli-varianos son héroes de
la patria.
-Los llaneros que pelearon en la guerra de Independencia no
eran hombres co-munes, sino héroes invencibles.
-Todos los héroes guerreros revolucio-narios de América Latina
se parecen, son como hermanos: Pancho Villa, Emiliano Zapata,
Angel Urtado, Sandino, Arévalo Cedeño, Maisanta.
-Todos los héroes latinoamericanos lu-charon por los mismos
ideales de liber-tad, contra el imperialismo.
-El nuevo héroe libertador de la historia latinoamericana es
Hugo Chávez.

a la disyuntiva histórica contemporánea, se afirma cual "verdad evidente", que no hay más que una opción: o nos liberamos del modo de vida que impone el imperialismo o la civilización desaparecerá. Lo cual, parecería coincidir con diversos planteamientos escatológicos postmodernos que emergen de discursos distintos, tanto del político ecológico-conservacionista, como del cristianismo latinoamericano, que nos advierten: uno sobre el recalentamiento global y sus consecuencias catastróficas a corto y mediano plazo, para la sobrevivencia de los ecosistemas naturales y las condiciones de vida en nuestro planeta y el otro sobre el Apocalipsis bíblico. Sin embargo, ello no emergió explícitamente en las producciones discursivas presidenciales aquí consideradas.

Todas las creencias registradas sobre el tópicoobjeto Los Héroes, fueron positivas y su contenido semántico se correspondió coherentemente con las construcciones discursivas vinculantes: La Guerra, La Revolución y La Historia. Los Héroes, fueron construidos discursivamente según la misma retórica a-temporal y descontextualizadora, empleada con esos tópicosobjetos anteriormente analizados, presentándolos como arquetipos, antepasados míticos que trascienden el espacio-tiempo histórico encarnándose luego en distintos personajes históricos que se ven hermanados "por los mismos ideales de libertad" y por su lucha revolucionaria contra los imperios. Dentro de esta temporalidad circular, emerge la figura de un "nuevo héroe libertador de la historia latinoamericana": el Presidente Chávez. De esta forma se cierra la trama discursiva oficial que construye de manera consistente una apología oficial de La Guerra, en nombre de la paz, la libertad y la soberanía plenas, de las cuales se afirma que sólo podrían lograse en el marco de una sociedad socialista dirigida por el 
pensamiento preclaro, único, del héroe refundador de la Patria, el Presidente-Comandante Hugo Chávez.

\section{Conclusiones}

La Guerra emergió como un aglutinante semántico de primer orden en la retórica discursiva presidencial. De forma recurrente y sistemática, las producciones discursivas del Presidente Chávez analizadas (1) hablaron de: estrategia, movimiento, combate, enemigo, victoria, lucha armada, paz, socialismo, capitalismo salvaje, táctica, comando, línea de batalla, choque de fuerzas, conflicto, guerra asimétrica, patria, batallones, misiones, objetivos, blancos, derrota, ofensiva, aliados, frente, emboscada, muerte, patriotas, libertad, acción militar... Términos todos, que hacen parte de la jerga militar con la cual se confecciona el discurso de la guerra, entendiendo junto con Glucksmann (1974, p. 52), que "El discurso de la guerra funda su autonomía al evaluar todo como un juego de fuerzas a partir de la lógica conflictiva irremediable que supone la existencia de al menos dos adversarios que se reconocen como tales beligerantes". Justamente, el discurso retórico oficial sobre La Guerra, encuentra su justificación ideológica y estratégica, en la posición defensiva que el gobierno del Presidente Chávez debería implementar "contra el imperio" de los USA y "contra los enemigos internos de la Revolución Bolivariana". En cuanto a la relación que existiría entre la violencia social que se vive en Venezuela y la violencia simbólica expresada en las alocuciones presidenciales, sería poco sensato establecer una relación causal simple y directa entre una y otras. No obstante, interpretamos que la reiteración sistemática y continua del discurso oficial en todos los medios de comunicación social venezolanos (2), afirmando que La Guerra "contra el Imperio de USA" y "los enemigos internos" es históricamente legítima, necesaria e indispensable para el triunfo de la Revolución Bolivariana socialista y para acabar con las desigualdades de clase y la pobreza, constituye una violencia simbólica sostenida por el discurso oficial, la cual propiciaría: 1) incrementar el resentimiento social de la mayoría de la población venezolana mediante la polarización político-ideológica explícita en el discurso presidencial, la cual sigue siendo excluida del reparto socio-económico de los beneficios petroleros por parte del Estado venezolano desde mediados del s. XX hasta nuestros días, 2) la construcción de identidades sociales dicotómicas irreconciliables ("chavistas, revolucionarios, patriotas"; Vs "anti-chavistas, contra-revolucionarios, antipatriotas, oligarcas"), en función de la adhesión o no a un proyecto político radical: el Socialismo del Siglo XXI ("Patria, Socialismo o muerte").

\section{Notas}

1 Debe destacarse el hecho poco frecuente que, en las dos alocuciones presidenciales aquí analizadas (y seleccionadas al azar), hubo muy pocas creencias registradas alrededor de la oposición política del gobierno, lo cual implicó que no se construyera discursivamente ningún tópico-objeto al respecto.

2 En Venezuela, las alocuciones presidenciales ocurren diariamente, sea mediante declaraciones, propaganda oficial, extensas cadenas radio-televisivas para transmitir todo tipo de eventos oficiales, o el programa dominical "Aló Presidente", cuya duración promedio es de 4-5 horas.

\section{Referencias}

Barthes, R. (1970). Mythologies. Paris: Seuil.

Billig, M. (1991). Ideology and opinions: studies in rhetorical psychology. London: Sage.

Billig, M., Condor, S., Edwards, D., Gane, M., Middleton, D., \& Radley, A. (1988). Ideological dilemmas. London: Sage.

Bourdieu, P. (1988). Espacio social y poder simbólico. Cosas Dichas. Argentina: Gedisa.

Briceño, R. (2007). Violencia urbana en América Latina: Un modelo sociológico de explicación. Espacio Abierto, 16(3), 541-574.

Coronado, D. (2007). La violencia en la sociedad contemporánea. Espacio Abierto, 16(3), 417-440.

d'Aubeterre, L. (2003). Ciudad, discursividad, sentido común e ideología: un enfoque psicosocial de la cotidianidad urbana. Espacio Abierto, 12(2), 168-186.

d'Aubeterre, L. (2007, otoño). La construcción discursiva de la otredad del "indio" en Ciudad Guayana: estudio de creencias y sentido común sobre los Warao indigentes urbanos. Athenea Digital, 12. Acceso en 07 de noviembre, 2007, en

http://psicologiasocial.uab.es/athenea/index.php/atheneaDigital/ article/viewArticle/401

Eliade, M. (1978). Mito y realidad. Barcelona: Guadarrama.

Fishbein, M. \& Ajzen, I. (1975). Beliefs, attitude, intention and behavior. Reading, MA: Addison-Wesley.

Gadamer, H.G. (1992). Verdad y método II. Salamanca: Sígueme.

Gergen, K. \& Keith, D. (1985). The social construction of the person. N.Y.: Springler.

Gluksmann, A. (1974). Le discours de la guerre. Paris: Coll $10 / 18$.

Kaés, R. (2000). La violencia está en el origen de todas las instituciones. Sonó una bofetada pero nadie intervino. Acceso en 21 de marzo, 2007, en

http://www.pagina12.com.ar/2000suple/psico/00-88/00-08-31/ psico01.html

Kretschmer, E. (1921). Configuration et pensée. Paris: Gallimard.

Marx, K. (1966). Oeuvres choisies. Paris: Gallimard.

Montero, M. (Coord.). (1994). Construcción y crítica de la psicología social. Madrid: Anthropos.

Mora J. \& Rodríguez R. (2004). Violencia e inseguridad: un dilema ético y político. Casa del Tiempo. Acceso en 13 de abril, 2007, en

http://www.difusioncultural.uam.mx/revista/abr2004/mora. $\mathrm{html}$ 
Páez, D., Valencia, M., Morales, L., Sarabia, J. \& Ursua, E. (1998). Teoría y método en psicología social. Barcelona: Anthropos.

Venezuela. Ministerio del Poder Popular para la Comunicación y la Información. (2007). Programa Aló Presidente n. 285 (10-06-07). Acceso en 17 de mayo, 2007, en http://alopresidente.gob.ve/component/option,com_docman/Itemid,0/ task,doc_view/gid,301/

Venezuela. Ministerio del Poder Popular para la Comunicación y la Información. (2008). Programa Aló Presidente n. 300 (13-01-08). Acceso en 26 de febrero, 2008, en http://alopresidente.gob.ve/component/option,com_docman/Itemid,0/ task,doc_view/gid,347/

World Health Organization (WHO). (2002). Wold report on violence and health. Geneva: Autor.

Luis Alberto d'Aubeterre Alvarado es Maîtrise en Psychologie, (1980): Université de Paris-VIII-Vincennes. Francia. Diplôme d'Etudes Supérieures Spécialisées,
(1981): Université de Paris-VII-Censier. Francia. Doctor en Psicología, (2001), en la Universidad Central de Venezuela. Desde 1992 es Docente Investigador Asociado del Centro de Investigaciones Antropológicas de Guayana, Universidad Nacional Experimental de Guayana-UNEG. Desde el 2005 es Coordinador del Centro de Investigaciones Antropológica de Guayana. Sede UNEG-Chilemex. Urb. Chilemex, Calle Chile. Puerto Ordaz, Edo. Bolívar-Venezuela. Email: ldaubete@gmail.com e ldaubete@uneg.edu.ve

Violencia social y discurso político presidencial venezolano: un estudio psicosocial

Luis Alberto d'Aubeterre Alvarado

Recebido em: 22/09/2008

Revisão em: 20/05/2009

Aceite final em: 13/06/2009 